\title{
The Study of Full-time Professional Postgraduate Training Mode in Local Universities and Colleges
}

\author{
Jian Wei ${ }^{a}$, Hanyin Mao \\ Graduate Education Department, Guangxi University of Science and Technology, \\ Liuzhou, Guangxi, 545006, China) \\ a781642983@qq.com
}

\begin{abstract}
The full-time Professional postgraduate education of local universities in Guangxi started late, and the foundation is weak. In the context of fast expansion, the postgraduate education of local universities will soon be in difficulty, if the universities won't develop with their characteristics. And the full-time Professional graduate students will become neither academic nor applied. In order to support the local economic, in particular the development of the North Bay Economic Zone, the current training mode should be changed and develop with their characteristics. So the following should be made clear: the admission pageant system, making clear the cultivation target, practical ability and professional skills, dual tutors, and training quality evaluation system.
\end{abstract}

Keywords: local universities; full-time professional postgraduate; training mode, practical ability, professional skills, dual tutors.

\section{Introduction}

Since the North Bay Economic Zone Development Plan had been approved, Guangxi has new development opportunities. The international economic cooperation zone is made up of four cities and two logistics centers, and its goal is to be the logistics base, business base, processing and manufacturing base, and information exchange center in China-ASEAN cooperation zone, which requires a large number of professionals as strong support. On the other side, with the fast development of the postgraduate education in our country, the employment in local colleges gradually becomes a big problem because the local colleges are weak on foundation and can't coordinate the local development, either. Some of the graduates in the colleges can't adapt to the current the needs of social development. They are neither academic nor applied, which causes a huge waste of education resources. In order to solve the problem of supply and demand and use education resources rationally and effectively, this paper explores the several aspects of graduate education of local colleges and tries to find the appropriate training mode, which can improve the training quality and support the personnel needs of North Bay Economic Zone.

Since the year of 2009, the full-time professional degree graduate education starts in our country. Now in some universities, this kind of education develops very fast, and accumulates a lot of experiences, such as the multi-objective enterprise-embedded training mode in Tianjin University of Commerce, which combine colleges and enterprises[1],the spiral promotion training mode in Nanjing University of Posts and Telecommunications[2].Many graduate managements have a variety of beneficial exploration. They research on training objectives, teaching method, dual tutors, evaluation system, and so on. Based on the service to the local economy, the article focuses on the courses, practice and admissions.

\section{The Problems of Full-Time Professional Graduate Education in Local Universities and Colleges}

\subsection{The defects in training objectives and curriculum}

\subsubsection{Training objective}

The training objective of academic graduate education is to train scientific elite, and emphasize the ability of innovation so that they can continued to struggle for science research. But in many 
universities and colleges, the training objective of full-time professional postgraduate is still not clear.Teachers still tend to academic postgraduate training objectives.

\subsubsection{Curriculum}

Although some universities and colleges have modified their training objectives in order to adapt the current of social development, quite a few colleges change in form but not in content, which mainly in curriculum. Due to the local universities and colleges are weak on faculty strength, in addition to the degree courses, many courses are based on the existing faculty strength. What's more, the courses are not fit for the local economic so the postgraduates can't acquire the frontier knowledge. The courses lay particular stress on theory, and lack of practical knowledge.

\subsection{The views of graduates and the way of learning}

\subsubsection{The views of graduates}

The foundation of students in local universities and colleges is ralatively weak because the source of students is variety. There are fresh undergraduates, equivalent graduates and college students who have worked for no less than two years, and equivalent graduate. The universities and colleges they graduate from are in different level. The purpose of studying is different, some really want to learn high-level knowledge and cultivate their ability of research and innovation, some just want a diploma.

\subsubsection{The way of learning}

Many graduates is ambiguous on how to learn, considering a continuation of undergraduate course, so they still carry on the undergraduate course, just follow the teacher's teaching, learning only textbook knowledge, but not focus on how to carry out scientific research.Some graduates adjust from academic graduates, they have no professional consciousness.

\subsection{The construction of teachers' team}

Full-time professional degree graduate education has just started several years, many colleges and universities is relatively lacking in the aspect of teachers. According to the requirements of training goal, we must take the dual tutorial system, and both tutors should have professional ability. The school tutor and off-campus train the students together, making their respective advantages complementary to each other. Despite all the schools are equipped with dual tutors, according to the requirements, but many of them become a mere formality. Because the tutors are lack of face-to-face communication, the training target is unclear.School tutors are only responsible for learning in the school,on the other side,off-campus tutors are just for the outside practice.Both do not participate in the whole training process, and the training is incomplete.

\section{Countermeasures and Suggestions}

\subsection{Attract high quality postgraduates and improve the quality of postgraduates}

Reform the enrollment system, and improve the quality of postgraduates. First of all, attract quality postgraduates in the form of high scholarship. Secondly, in meeting the basic conditions for admission, the entrance can tend to recruit candidates with prior work experience or on-the-job examinee, because their occupation are more obvious. Thirdly, carry on a practice of assessment in the second interview, which excluding some candidates who adjust just for lower grades, but in fact they have no interest in the field. Fourthly, give full play to the tutors' role in the second interview selection.

\subsection{Courses should be practical and professional}

According to the professional postgraduate training goal, the curriculum should be oriented by career, pay attention to the practical and professional teaching content. Course content should give priority to theories and cases. Appropriate theoretical teaching can improve the level of theory. At the same time, increase the case teaching, and consummate case teaching database gradually. Hire off-campus professionals involved in case teaching to improve the postgraduates' application ability and practice ability.

\subsection{Perfect the dual tutorial system, strengthen the communication and exchanges}

Compared with the academic postgraduates, professional postgraduates pay more attention to practical application ability, so it is necessary to establish and make perfec of the dual tutorial system. 
School teachers guide the postgraduates have rich theoretical basis and teaching experience, cultivating postgraduates having a certain scientific research ability. Off-campus tutors have a wealth of practical experience, who can cultivate postgraduates practical ability. Each of them is very important, so we must select the tutors strictly, cultivate them seriously, strengthen the management of them, perfect the evaluation system of them, and establish incentive mechanism. The two tutors must strengthen the communication to discuss how to do a good job of training. Strengthen practice in their learning process of theory, and theories guide practice in the process of practice. Do not disconnect, and link up organically.

\subsection{Strengthen the construction of joint training bases of postgraduate}

Postgraduate joint training bases can use the conditions of enterprise, institution, science and technology, platform effectively, such as various kinds of high quality resources, which can make up for the inadequate number of school teachers. At the same time, postgraduates study in the real work scene, do the real work, they can get exercise and improve their innovation ability and actual application ability.Their efforts can provide technical services for the local economic,social development and decision support ${ }^{[3]}$. For example, the School of Foreign Languages of Guangxi University of Science and Technology has set up two joint training bases: technology postgraduate joint training base and translation translation joint training base, although the cultivation of Master of Translation has only two years. One of them is established jointly with the local well-known enterprises, another is established with the foreign affairs office. This kind of actual combat training makes a good exercise for the strain ability and comprehensive ability ${ }^{[3]}$.

\subsection{Optimization of training process, improve the quality control}

The training process of master of professional and academic graduate are difference, we must distinguish the two strictly at the beginning. According to the development request of the master of professional,it doesn't like academic training focuses on the cultivation of academic ability, so as to avoid the failure of academic ability and application ability training. Make full use of the limited time at school and in the units or practice bases, arrange everything reasonably, make the effective training, optimize the training process.

To achieve this goal, we should strengthen and improve the quality control. On the aspect of univerities, establish a tutors-steering team to monitor all the training links. The work does not become a mere formality. The team must establish the work strickly,especially the off-campus practice monitoring, and implement the responsibility of supervision.

3.6 Perfect the evaluation system, select the superior and eliminate the inferior

Evaluation system is very necessary for any work. From two aspects of spiritual and material, reward excellent papers or other scientific research achievements, which can inspire the enthusiasm of tutors and postgraduates. No matter when people do a job, everyone wants to get sure, which can prove their efforts were not in vain. But for the performance of ideology and moral character, academic or professional quality is poor, schools should evaluate and education carefully. Dare to eliminate thoes who are unable to adapt to.

\section{Conclusion}

The emergence of full-time professional degree graduate education is complied with the need of social development. The guidance of full-time professional degree graduate students is cultivating qualified industry backbone. Based on the local economy and the service for local economy, it achieves the goal of training. In advance areas, full-time professional degree graduate education have a development history of nearly 10 years. Training mode is more mature. The education made due contributions to the development of economy. But in guangxi, especially in our school, the development history is short, various aspects of work are in the start stage, we need to do hardly. Although guangxi are relatively backward in economy and education, the government makes great efforts continuously, and the effect is significant, especially the construction of the Beibu Gulf Economic Zone is remarkable. If the local universities and colleges want to survive and develop, they 
must take the initiative to adapt to the economic and social development of the urgent needs of the high-level talents, and provide a more solid talent guarantee and intellectual support.

\section{Acknowledgements}

Thanks for the fund project: Innovation Project of Guangxi Graduate Education (JGY2015119).

\section{References}

[1]Zhang Su-yuan.Research on the Multi-Objective Enterprise-Embedded Training Mode of Profession Master[J]Theory and Practice of Education.Vol.36(2016).No.9,p. 15-16.

[2]Xiaolong Xue,Yuanyuan Kong,Menge Li. Professional Postgraduates "Screw Lift Type" Training Mode [J]Higher Engineering Education Research.2011(2),p.149-153.

[3] 2015-2016 Quality of the Annual Report of Postgraduate Education in Guangxi University of Science and Technology.

[4]Jianhong Bi,Yu Xiao,Zhenjian Ji,Jianwen Wei. Present Situation, Problems and Countermeasures of Full-time Professional Degree Postgraduate Education[J]Education Teaching Forum.No7 (Feb.2016), p.277-278. 